\title{
Assessment of the changes in the stress related salivary cortisols levels induced during different dental procedures
}

\begin{abstract}
:
Aims and objective: Anxiety ,fear and pain assessment is essential in day to day Dental practice. The present study evaluated the stress related salivary cortisols levels induced during scaling, tooth preparation and surgical flap elevation in Periodontally compromised subjects

Methodology: The salivary cortisol level were assessed in 80 patients ,out of which 40 patients were healthy patient who do not require any Dental treatment and 40 patients who underwent Scaling , tooth preparation and surgical flap elevation in Periodontally compromised subjects

The groups divided were as follows .

Group 1: control group with no treatment and just the saliva sample was taken.

Group 2: The patients underwent scaling

Group 3: The patients underwent tooth preparation for fixed prosthesis

Group 4: The patients underwent surgical flap elevation in Periodontally compromised situation.

The salivary cortisol levels were assessed using Salivary Cortisol Enzyme Immunoassay Kit.

Results: The salivary cortisol level was highest in Group 4 followed by Group 2, Group 3 and least in Group 1.

Conclusion: The stress level was lowest in healthy patient and highest when patient under went surgical flap elevation in Periodontally compromised subjects Dentist should try to minimize subject anxiety and stress to great extent.
\end{abstract}

Key words: Anxiety, Tooth Preparation,Cortisol level and Flap elevation

\section{Introduction :}

The stress disturbances are the common mental disturbances[1] The Dental environment is a source of stress for any patient. [2,3] The stress control is essential in patients to elude the loss of motivation for Dental procedures. The stress reaction may develops cortisol dysfunction and widerange pain.[4] It may results in change in behavior in children and affects the Dental procedures and the stress ripostes are not invariably hostile.[5] By downgrading stress of Dental procedures the patients will get their Dental procedures done.[6,7] Saliva can be used as a sample for stress-releated substance measurement because its collection is not invasive and not harmful, and can be collected with little

\begin{tabular}{|l|c|}
\hline \multicolumn{3}{|c|}{ Access this article online } \\
\hline $\begin{array}{l}\text { Website: } \\
\text { www.ujds.in }\end{array}$ \\
\hline $\begin{array}{l}\text { DOI: } \\
\text { https://doi.org/10.21276/10.21276/ujds.2020.6.2.15 }\end{array}$
\end{tabular}

efforts than blood sampling. Stress-connected substances incorporated in saliva include chromogranin A ( $\mathrm{CgA})$, secretory immunoglobulin A ( $\lg \mathrm{A})$, and salivary amylase,

\author{
${ }^{1}$ PHUKELA S $S,{ }^{2}$ RITWAL $P,{ }^{3}$ DHALL $R$, \\ ${ }^{4}$ YADAV P, ${ }^{5}$ MADAN $R,{ }^{6}$ YADAV J \\ ${ }^{1,2,5,6}$ Department of Prosthodontics, Faculty of Dental \\ Sciences, SGT University, Gurgaon \\ ${ }^{3}$ Department of Prosthodontics, Himachal Institute of \\ Dental Sciences, Poanta Sahib \\ ${ }^{4}$ Department of Prosthodontics, Indraprastha Dental \\ College, Sahibabad
}

Address for Correspondence: Dr. Sumit Singh Phukela House No 4 Gopi Nath Bazar Delhi Cantt110010 E-mail: phukelasumit@yahoo.com

Received : 02 August 2020, Published : August 2020

How to cite this article: Phukela, S. S., Ritwal , P., Dhall, R. S., Yadav , P., Madan, R., \& Yadav, J. (2020). Assessment of the changes in the stress related salivary cortisols levels induced during different Dental procedures. UNIVERSITY JOURNAL OF DENTAL SCIENCES, 6(2): 39-2. 
catecholamine and cortisol.[8,9] There is marked contrast in patients reaction to stress in children who are involved not only in a agony procedure but also a painless treatment. The anxious tense feeling while in the Dental chair and the procedure itself can develop anxiety. The outcome with application of anesthesia and with agony procedures are unavoidable. Dental scenario can be origin of stress for young patients. The stressful state may develop panic and worry in patients.[10] Therefore the anxiety strand is more in patients undergoing Dental treatment and this pressure vary in the consecutive visits that persue to rely upon to what they are open to, during these visits. Dental treatment is considered as anxiety producing and stressful, which has related to fight response in adults. Very few studies have been conducted to evaluate relationship between stresses during dental treatment. The cortisol nourishes and recalls the frightening participation of Dental treatment. There is persistence of powerfull touching revoke happening in fear and post traumatic pressure therapy. Gaur A reported that it is not always that aging helps in adjustment of stress hormone cortisol during psychosocial disturbance. There is lesser hopefulness , anxiety, mental disorder, depression with severe pressure, distress multipled with raised cortisol level.[11] The cortisol is produced in response to anxiet, pressure or stress by adrenal gland. The cortisol is also liberated in conditions like getting up early morning, exertion and acute pressure or tension. Dental anxiety, fear, stress results in negligence of proper Dental treatment care. Need of the study; The results of studies conducted by different researchers to evaluate relationship between stresses during dental treatment were mixed and conflictory

Therefore the present study evaluated the changes in the stress related salivary cortisols levels induced during scaling, tooth preparation and surgical flap elevation in Periodontally compromised subjects ; An In Vivo Study

\section{Aims and Objectives:}

The present study comparatively evaluated salivary cortisol level in patients under going scaling, tooth preparation for fixed prosthesis, and surgical flap elevation in Periodontally compromised situation.

\section{Material and Method:}

The present study was conducted in SGT DENTAL COLLEGE, SGT UNIVERSITY.

There was 80 participant ( 40 control and 40 patients with Dental problems )who volunteered in the present study.The sample size was calculated keeping a confidence interval of
$95 \%$ and a power of atleast $80 \%$. The sample size was chosen to be 60 using the previous studies done by Gaur A,Kumar JS,R. Nair Agrawal VM[11]. All concerned participant were being asked to give relevant Medical and Dental history. 80 patients age group ranging 20-30 were included in the study. The investigation motive was prior informed to patients requesting them for accumulation of saliva sample. These patients underwent scaling, tooth preparation for fixed prosthesis and and surgical flap elevation in Periodontally compromised situation.

They were demarcated into 4 groups

Group 1: control group with no treatment and just the saliva sample was taken.

Group 2: The patients underwent scaling

Group 3: The patients underwent tooth preparation for fixed prosthesis

Group 4: The patients underwent surgical flap elevation in Period on tally compromised situation

The saliva was collected 5 minutes before patients sat on Dental chair for group 1 subjects, however for group 2, group 3 and group 4 subjects saliva was gathered 10 minutes after commencement of Dental procedures. All the participants were informed to accumulate saliva samples in polypropylene vials and stocked in freezer. Around $1.0 \mathrm{ml}$ of non-revivifying saliva was assembled in a sterile tube and frozen latter at 20 degree centigrade for further investigation The salivary cortisol levels were assessed using Salivary Cortisol Enzyme Immunoassay Kit (Salimetric TM, LLC State college PA ,USA)[10] The software used for the statistical analysis were SPSS (statistical package for social sciences).

\section{Statistical Analysis:}

The statistical analysis were done using One-way ANOVA test and Post-hoc tukey test

Level of Significance (p-value)

?-value $<0.05$ - Significant

\section{Results:}

The mean cortisol level was compared among the different groups using the one-way ANOVA test with post-hoc tukey test for the inter-group comparisons. There was a significant difference i mean cortisol level between the different groups. The mean cortisol level was significantly more among Group 4 which was significantly more than group 2 which was significantly more than group 3 which was significantly more than group 1.Table 1 and Grap 1 ) 
Table 1: Comparative mean salivary cortisol level(ng/ml) for Group 1, group 2, group 3 and Group 4.

\begin{tabular}{|c|c|c|c|c|c|}
\hline Groups & Number & Mean & SD & \multirow[t]{3}{*}{ F-value } & \multirow[t]{2}{*}{ p-value } \\
\hline Group 1 & 40 & 9.42 & 2.98 & & \\
\hline Group 2 & 40 & 18.45 & 4.12 & & \multirow{3}{*}{$<0.001{ }^{*^{\mathrm{a}}}$} \\
\hline Groun 3 & 40 & 13.11 & 3.67 & \multirow[t]{2}{*}{32.242} & \\
\hline Group 4 & 40 & 25.50 & 5.89 & & \\
\hline \multicolumn{5}{|c|}{ Group 1 vs Group $2^{b}$} & $0.011 *$ \\
\hline \multicolumn{5}{|c|}{ Group 1 vs Group $3^{b}$} & $<0.001^{*}$ \\
\hline \multicolumn{5}{|c|}{ Group 1 vs Group $4^{\mathrm{b}}$} & $<0.001 *$ \\
\hline \multicolumn{5}{|c|}{ Group 2 vs Groun $3^{b}$} & $0.039 *$ \\
\hline \multicolumn{5}{|c|}{ Group 2 vs Group $4^{\mathrm{b}}$} & $<<0.001^{*}$ \\
\hline \multicolumn{5}{|c|}{ Group 3 vs Group $4^{b}$} & $0.011^{*}$ \\
\hline
\end{tabular}

aOne-way ANOVA test bPost-hoc tukey test* Significant difference

Graph 1: Comparative mean salivary cortisol level(ng/ml) for group 1, group 2, group 3 and group 4 .

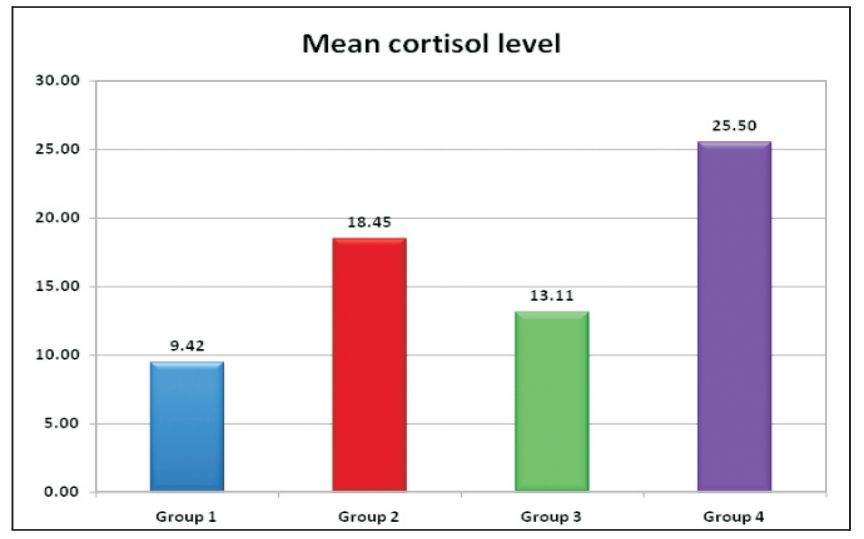

\section{Discussion:}

The cortisol nourishes and recalls the frightening participation of Dental treatment. Shira Meir Drexler, Christian J Merz, TanjaC,Hamacher - Dang, Martin Tengentoff, Oliver $\mathrm{T}$ in 2015[12], stated that there is endurance of powerful touching recallhappening in fear and post traumatic pressure disarray. Lai JCL in 2014[13] reported that the adaptation in stress hormone ,cortisol to critical psychosocial pressure is not always a result of aging. Severe pressure and raised cortisol level multiplies the possibility for depression, mental disorder , anxiety, and lesser life hopefulness. The cortisol is delivered in reaction to anxiety, pressure or stress by adrenal gland. The cortisol can also be emancipated in situations like getting up early morning, exertion and acute pressure or tension. The cortisone enables the body for attack or flying reaction by immersing it with glucose, providing an instant energy origin to large muscles. The cortisol hinder insulin release in an aim to stop glucose from being stocked approving instant release [14]. Gaur A reported that it is not always that aging helps in adjustment of stress hormone cortisol during psychosocial disturbance The results of studies conducted by different researchers to evaluate relationship between stresses during dental treatment were Contradictory.

In the present study there was significant difference in cortisol level in control group compared to all study groups \{group 2 , group 3 and group 4$\}$. The salivary cortisol level was highest in Group 4(subjects with surgical flap elevation in Periodontally compromised situation), followed by Group 2(subjects who underwent scaling), Group 3(subjects who underwent tooth preparation for fixed prosthesis) and least in Group 1(control). These results are similar to studies done by Padmanabhan V, RaiK,Hedge AM[10] and Phukela SS, Ullah A, Srivastava PK, Dua M, Setya G, Dua A[15] The study group (group 2,group 3 and group 4) opened to Dental treatment develops in an elevation of salivary cortisol in contrast to control group with no treatment wherein just the saliva sample was taken. Dental treatment raises tension and uneasiness level which further elevates salivary cortisol These results are similar to studies done by Phukela SS, Ullah A, Srivastava PK, Raina B, Setya G, Thareja SS, Pawha R[16] and Phukela SS, Setya G, Yadav G, S ehgal M,Dhall RS, Srivastava PK, UllahA, Dua M[17]. Among the study groups \{group 2, group 3 and group 4\}, Group 4(subjects with surgical flap elevation in Periodontally compromised situation) produced highest cortisol level. The cortisol level was raised more in Group 4 (subjects with surgical flap elevation in Periodontally compromised situation ) compared with subjects in Group 2 (subjects who underwent scaling) The probable reason may be that the local anaesthesia used for these patients for carrying out Dental procedure raised stress and anxiety level in these subject resulting with raised cortisol level.

The cortisol level was raised more in Group 2 (subjects who under went scaling) compared with subjects in Group 3 (subjects who underwent tooth preparation for fixed prosthesis). The probable reason may be that the fear of seeing blood while scaling raised cortisol level in these subjects.

The cortisol level was raised more in Group 3 (subjects who underwent tooth preparation for fixed prosthesis ) compared with subjects in control group. The probable reason may be that the vibrations and sound of air rot or hand piece during the cavity preparation raised cortisol level in these subjects. Therefore it can be concluded that the stress level was highest when patient under went surgical flap elevation in Periodontally compromised situation followed by Group 2 (subjects who underwent scaling), Group 3(subjects who underwent tooth preparation for fixed prosthesis). The lowest 
cortisol level (stress level) was seen in healthy patients who did not got any treatment done. The salivary cortisol can be one of the reliable indicator of stress detector.

\section{Conflict of Interest:}

No potential conflict of interest relevant to this article was reported.

\section{References:}

1. EngetV, PlessowF, MillerR, Kirschbaum C, Singer T. Cortisol increase in emphathic stressis modulated by emotional closeness and observation modality. Psychoneuroendocrinology Journal;2014;Volume 45;195-201

2. Mufti N, Mufti S, Mufti K. Stress and anxiety in patients undergoing extraction International Journal of Oral Care and Research ,2017;5(1)75-77

3. PatilS J, Shah PP Patil JA, Shigli A, Patil AT, Tamagond SB. Assessment of the changes in the stress related salivary cortisols levels to the various Dental procedures in children J Indian Soc Pedod Prev Dent $2015 ; 33(2) 94-99$

4. Hannibal KE,Bishop MD. Chronic stress, cortisol dysfunction ,and pain a psychoneuroendocrine rationale for stress management in pain rehabilitation. Phys Ther 2014;94(12)1816-25

5. Buchanan T W, PrestonSD. Stress leads to prosocial action in immediate need situations Front BehavNeurosci 2014;8;5

6. Klingberg G, Berggren U, Carlsson SG, Noren JG. Child Dental fear: cause-relatedfactorsand clinical effects. EurJ OralSci 1995;103:405-12.

7. Kiyoshi Ohura, Tadashige Nozaki, Mitsuko Shinohara, Kiyoshi Daito ,Mie Sonomoto, Michiharu Daito - Utility of salivary biomarker for stress induced by Dental treatment. Japanese Dental Science Review. February2012, Vol.48(1):14-17, doi:10.1016/j.jdsr.2011.06.001.

8. Taani DQ, El-Qaderi SS, Abu Alhaiji ES. Dentalanxiety in children and its relationship to Dental caries and gingival condition. Int J Dent Hyg 2005;3:83-7.

9. Yamaguchi M, Kanemori T, Kanemaru M, Takai N, Mizuno Y, Yoshida H. Performance evaluation of salivary amylase activity monitor. Biosens Bioelectron 2004;20:491—7.

10. Padmanabhan V, RaiK, Hedge AM; Stress responses in Children during Endodontic Treatment. J Pediatr Dent 2013;1;14-8

11. Gaur A,Kumar JS,R .Nair Agrawal VM .Estimation of salivary cortisol levels and pscycological assessments in patients with oral lichen planus JIndian Acad Oral Med Radiol 2018;30;14-7 12.Shira Meir Drexler, Christian J Merz, Tanja C, Hamacher -Dang, Martin Tengentoff, Oliver TW olf. Effects of cortisol on reconsolidation of reactivatedfear memories Neuropsychophrmacology 2015;10.1038/npp2015.160

13. Lai JCL Psycosocial stress and salivary cortisol in older people ;a brief review .Aging Sci $2014 ; 2 ; 120$, doi 10.172/2329/8847.1000120.

14. Aronson D. Cortisol-its role in stress, inflammation and indication for diet therapy. Todays Dietician 2009, Vol 11,pg 38

15. Phukela SS ,Ullah A, Srivastava PK , Dua M, Setya G ,Dua A Monika Nervousness; Pressure Ripostes in Patients During Conventional Dental Treatment and Long Duration Dental Procedures: An in Vivo Study J Res Adv Dent 2017;6:2:61-65

16. Phukela SS, Ullah A, Srivastava PK, Raina B, Setya G, Thareja SS , Pawha R , Moon V Salivary Cortisol Response to Stress Induced During Periodontic, Endodontic and Prosthetic Procedures: An In Vivo Study J Res Adv Dent 2016;5:3:234-238.
17. Phukela SS, Setya G,YadavG, Sehgal M, Dhall RS,Srivastava PK, Ullah A, Dua M Estimation of Salivary Cortisol among subjects undergoing Scaling Restorative and Biopsy procedures: An In V i v o Study International Journal of Current Research,10,(10)74201-74204 